\title{
Genetic improvement of wheat grain quality at CIMMYT
}

\author{
Carlos GUZMÁN (ه), Karim AMMAR, Velu GOVINDAN, Ravi SINGH
}

Global Wheat Program, The International Maize and Wheat Improvement Center (CIMMYT), Texcoco C.P. 56237, Mexico

\begin{abstract}
The International Maize and Wheat Improvement Center (CIMMYT) is the global leader in publiclyfunded maize and wheat research and in farming systems based on these crops. CIMMYT leads the Global Wheat Program (GWP), which includes some of the largest wheat breeding programs in the world. The GWP has been successful in developing wheat germplasm that is used extensively worldwide. Wheat quality improvement is a central component of all the breeding efforts at CIMMYT and the Wheat Chemistry and Quality Laboratory represents an integral part of the breeding programs. Wheat quality is addressed at CIMMYT over the full range of this very wide and variable concept with milling, processing, end-use and nutritional quality targeted. Wheat progenitors and advanced lines developed by the breeders are assessed for diverse quality attributes, with the aim of identifying those that fulfill the requirements in terms of milling, processing, end-use and nutritional quality in different target regions. Significant research is conducted to make more efficient the integration of wheat quality traits in the breeding programs. The main topics being addressed are (1) methodologies to analyze grain quality traits, (2) genetic control and environmental effects on quality traits, (3) characterization of genetic resources for quality improvement, and (4) diversifying grain properties for novel uses.
\end{abstract}

Keywords biofortification, breeding, grain quality, wheat

\section{Introduction}

Wheat is one of the most important crops globally for food and nutritional security. For thousands of years, it has been a major staple food crop in Eurasia, and bread from the wheat grain, has been the sustainer of life for these populations. Currently, wheat is cultivated in almost all latitudes (from $67^{\circ} \mathrm{N}$ in Russia to $50^{\circ} \mathrm{S}$ in Chile) and almost all climatic regions, including wet, semiarid and

Received March 5, 2019; accepted March 25, 2019

Correspondence: c.guzman@cgiar.org arid (with irrigation) areas, or elevated regions in the tropics and subtropics ${ }^{[1]}$. It is also cultivated at altitudes as high as $3000 \mathrm{~m}$. In 2017, $771 \mathrm{Mt}$ of wheat grain was harvested from an area of 218 Mha, with a global average yield of $3.53 \mathrm{t} \cdot \mathrm{ha}^{-1\left[^{2}\right]}$. Two main wheat species are cultivated today: common or bread wheat (Triticum aestivum ssp. vulgare), which occupies around $93 \%$ of the total wheat grown area, and durum wheat (Triticum turgidum ssp. durum), which covers the remaining $7 \%$. The wide adaptability and relatively high yields of wheat have been key for the current dominance of this crop in the temperate regions. However, the success of wheat cannot be explained without taking into account the unique properties of dough made from wheat flour and semolina, which allow it to be processed into a range of products (e.g., bread, pasta, biscuits and noodles) and other processed foods. These products are the preferred, and often the dominant, food in many countries around the world ${ }^{[3,4]}$. Furthermore, there is an increasing demand for wheat in new markets beyond its region of climatic adaptation. In fact, wheat now provides $20 \%$ of the calories and $19 \%$ of the protein consumed globally by humans ${ }^{[2]}$.

\section{CIMMYT and the Global Wheat Program}

The International Maize and Wheat Improvement Center (CIMMYT), is the global leader in publicly-funded maize and wheat research and in farming systems based on these crops. Headquartered near Mexico City, CIMMYT works with hundreds of partners throughout the developing world to sustainably increase the productivity of maize and wheat cropping systems, thus improving global food security and reducing poverty. CIMMYT is a member of the CGIAR network and leads the Global Wheat Program (GWP), which includes some of the largest wheat breeding programs in the world. The first breeding program was initiated in 1945 by the late Dr. Norman E. Borlaug to alleviate Mexico's dependence on wheat imports. After 1956, when Mexico became self-sufficient in wheat production, Borlaug and his team developed semidwarf, high-yielding spring wheat cultivars that led to the Green 
Revolution in several regions (including South Asia and North Africa). These, so called, Mexican wheats markedly increased grain yield and undoubtedly contributed to alleviating global food shortages and famine that would have otherwise occurred at a much larger scale ${ }^{[5]}$. Currently the GWP collaborates with more than 200 national agricultural research institutions, nongovernmental and community-based organizations, seed sector organizations, regional research networks, private companies, advanced research institutions and other CGIAR centers, to provide farmers with the best seed, agronomy, training and information needed to increase productivity and grain quality. Over recent decades, the GWP has been successful in developing wheat germplasm that is used extensively worldwide, Lantican et al. ${ }^{[6]}$ showed that over 102 Mha GWP-derived cultivars were planted, corresponding to more than $50 \%$ of the total wheat cultivars released worldwide during 1994-2014.

Currently, three different wheat breeding programs are run by CIMMYT, bread and durum spring wheat breeding programs (centered in Mexico) and the winter bread wheat program (centered in Turkey). This article is focused on the activities of both spring wheat breeding programs. The priorities of these breeding programs are the continuous increase in grain yield potential, disease resistance, tolerance to abiotic stresses (such as drought and heat) and grain quality. To achieve continuous genetic gains for these traits, thousands of segregating populations are selected under drastically contrasting conditions using a shuttle-breeding scheme. This consists of alternating selection within segregating populations between two field stations, namely, Ciudad Obregon (Sonora in northwestern Mexico) and Toluca (Estado de Mexico in central Mexico). In addition to allowing two cropping cycles per year and considerably reducing the time necessary to generate wheat germplasm with fixed characteristics, this shuttle-breeding system is key to producing germplasm with wide adaptability. The cropping cycle in Ciudad Obregon runs from November to April, and in Toluca, from June to September. In Ciudad Obregon, selection is done for grain yield potential, leaf rust resistance and drought and heat tolerance, and Toluca works well to select breeding lines resistant to yellow rust and septoria. Once lines are genetically fixed through visual selection, tens of thousands are evaluated in yield trials under various testing conditions (including optimal conditions, different types of drought, and heat stress) before the best are selected for global distribution in international nurseries. The evaluation done in these stations is complemented by more testing performed in precision phenotyping systems located in other countries and managed in collaboration with national programs (e.g., Kenya for stem rust, Tunisia for septoria and Bangladesh for wheat blast), where CIMMYT germplasm can be exposed to pathogens and conditions that are not present in Mexico. In addition, all the data generated in these evaluations is complemented by the data collected by tens of national partners that evaluate CIMMYT germplasm in their own locations. These partners receive the international nurseries annually, which consist of the 50 best wheat genotypes generated by the breeding programs for particular wheat megaenvironments (including irrigated, semiarid and high rainfall) every year. National partners can use this wheat germplasm to improve their own germplasm or as directly released cultivars when appropriate.

\section{Genetic improvement of grain industrial quality}

As mentioned above, wheat quality is one of the key priorities of the CIMMYT breeding programs. Considering the global focus of the programs and the clear intention of developing germplasm that promotes the development of a value chain to alleviate poverty in developing countries, wheat quality is addressed at CIMMYT over the full range of this very wide and variable concept. Wheat quality can be defined differently by different stakeholders in the wheat chain in different countries. The stakeholders CIMMYT considers in its breeding programs include farmers, millers, food processors and consumers.

Subsistence farmers will mill and process the wheat grain to feed their families, and therefore these farmers will see end product appeal and organoleptic properties as the most important attribute of wheat quality. Commercial farmers, on the other hand, will value wheat quality characteristics that allow the sale of their grain at the best possible price. The system used to classify wheat grain in different classes or grades varies considerably between countries. It can be very simple, considering only grain soundness, or more complex and regulated as in wheat exporting countries such as Australia or Canada, where grain size and density, percentage of grains damaged, and protein content are crucial to obtain a specific quality grade associated with different, well-defined prices in the global market.

Millers are primarily interested, in the ability of a wheat grain to be milled at reasonable cost and to produce high levels of flour or semolina of suitable quality. In this case, quality means minimal contamination of the flour with the bran fractions (determined by the ash concentration). In this process, grain hardness, size, roundness and density are the most important traits ${ }^{[7,8]}$. Millers are also responsible for generating flour of the processing quality (the ability of a flour or semolina to be processed at minimum cost and to give a uniform product) demanded by the food processing industry. Very often millers need to blend and combine different types of grain (of diverse genetic and regional origin) differing in quality traits to produce the flour with the desired characteristics.

Wheat is used to make hundreds of different products worldwide, each one with specific grain quality 
requirements. In terms of processing quality, grain hardness and gluten visco-elastic properties (gluten strength and extensibility) are probably the most important traits. The food processors need to target the end-use quality that consumers demand. This will be extremely variable depending on the region. For example, dense durum breads are highly appreciated in some Mediterranean regions, whereas, high loaf volume bread with light crumb is preferred in the Americas. While yellow color is a desired trait in durum wheat semolina used to make pasta, it is undesirable in bread wheat flour to make bread or other products. Other consumers will be also interested in the processing conditions (artisanal or handmade vs. mechanized or industrial) and in the use of additives to modify the end-use quality. Nutritional quality is also becoming an important concern for consumers, and it is consequently becoming a priority for breeding programs.

Due consideration of all the complexities of the wheat quality concept is important before attempting genetic improvement in any breeding program. It is also necessary to understand the biochemical and genetic basis that define the different grain and flour quality traits. Probably, grain hardness and dough visco-elastic properties are the most important traits affecting industrial grain quality (which includes milling, processing and end-use quality). Wheat grains are usually classified in global or local markets as soft, hard or very hard (durum wheat). Grain hardness is determined by the presence of two small proteins named puroindolines encoded by the genes Pina-D1 and Pinb-D1. When both puroindolines are present, the grain texture is soft, but if either one is absent or altered by mutation, then the grain textured is hard. In the case of hard durum wheat, both puroindolines are absent due to the lack of the D genome in this species $^{[9]}$. Grain hardness will affect the milling process, flour particle size and water absorption, and partly define end-use quality (soft grain flour for cookies and pastries, hard grain flour for bread). In contrast, the dough visco-elastic properties (gluten elasticity and extensibility) are defined by the gluten content and composition. Gluten is formed mainly by the glutenins (divided in high and low molecular weight glutenins) and the gliadins, with the former normally associated with gluten elasticity or strength and the later with extensibility and viscosity. Most of the important genes controlling these proteins (e.g., Glu-1, Glu-3 and Gli-2) are well known and their different alleles have been associated to gluten quality characteristics (see Wrigley et al. ${ }^{[10]}$ for a complete review of wheat gluten). Other important quality traits such as starch pasting properties, grain and flour color, enzymatic activities, are now reasonably well understood and their genetic control elucidated.

The Wheat Chemistry and Quality Laboratory of CIMMYT is an integral part of the breeding process. The laboratory analyzes thousands of grain samples each year from both bread and durum wheat breeding programs. For bread wheat, the overall grain quality strategy has been to ensure suitable gluten quality (diverse levels of gluten strength combined with the required extensibility) at medium protein content levels, in semi-hard or hard grains. This set of quality parameters is preferred for most products in developing countries. The following traits are analyzed for the bread wheat breeding program: grain morphology (test weight and thousand-kernel weight), hardness (using an SKCS, Perten, Hägersten, Sweden), protein and moisture content (by NIR), PPO activity (by AACC method 22-85 performed with whole kernel), flour yield (using a Quadrumat Senior mill, Brabender, Duisburg, Germany), flour protein content and water absorption (by NIR and based on Guzmán et al. ${ }^{[11]}$ ), overall gluten quality (by SDS sedimentation), dough mixing properties (by mixograph), gluten strength and extensibility (by alveograph), and bread-making quality (straight dough method, AACC method 10-09). These tests provide a complete characterization of the breeding materials, which allows the breeder to make an effective selection of desirable germplasm. To make the selection process easier, the data generated is used to classify the breeding lines into five different potential end-use types (Table 1). For each type, there can also be subtypes based on protein content ( $a$ for medium-high and $b$ for mediumlow protein). Type 1 lines are white and red hard grain lines with strong gluten (alveograph $\mathrm{W}>300$ and $\mathrm{P} / \mathrm{L}$ ratio

Table 1 End-use type classification to facilitate breeding at CIMMYT

\begin{tabular}{|c|c|c|c|}
\hline End-use type & Products & Grain type & Gluten type \\
\hline 1 & Pan breads & Hard & Strong and extensible (alveograph $\mathrm{W}>300 ; \mathrm{P} / \mathrm{L}<1.3$ ) \\
\hline $2 \mathrm{a}$ & $\begin{array}{l}\text { Leavened breads, two-layer flat breads, dry } \\
\text { and fresh noodles }\end{array}$ & Hard & Medium-strong and extensible (alveograph $\mathrm{W}>200 ; \mathrm{P} / \mathrm{L}<1.1$ ) \\
\hline $2 b$ & Steamed bread (northern Chinese style) & Hard & Medium-strong and extensible (alveograph $\mathrm{W}>200 ; \mathrm{P} / \mathrm{L}<1.1$ ) \\
\hline 3 & Dense and flat breads & Hard & Medium-weak and extensible (alveograph $\mathrm{W}=150-200 ; \mathrm{P} / \mathrm{L}<1.0$ ) \\
\hline $4 \mathrm{a}$ & $\begin{array}{l}\text { Steamed bread (southern Chinese style) and } \\
\text { white-salted noodles }\end{array}$ & Soft & Strong-medium and extensible (alveograph $\mathrm{W}>200 ; \mathrm{P} / \mathrm{L}<1.1$ ) \\
\hline $4 b$ & Biscuits and cakes & Soft & Weak and extensible (alveograph $\mathrm{W}<100 ; \mathrm{P} / \mathrm{L}<0.7$ ) \\
\hline 5 & Household use or utility wheat & Hard or soft & $\begin{array}{l}\text { Weak (in hard grain genotypes) (alveograph } \mathrm{W}<150) \text { and tenacious } \\
\text { gluten }(\mathrm{P} / \mathrm{L}>1.3)\end{array}$ \\
\hline
\end{tabular}


$<1.3$ ) suitable for pan type breads in mechanized industry. Type $2 \mathrm{a}$ lines ( $>11.5 \%$ protein) are suitable for leavened breads produced in semi-mechanized industry (e.g., baguettes and supermarket breads), two-layer flat breads (baladi), and dry and fresh noodles (alkaline, white and instant). Type $2 \mathrm{~b}$ lines are suitable for single-layer flat breads (chapatti) and steamed bread (northern Chinese style) (both Types $2 \mathrm{a}$ and $2 \mathrm{~b}$ lines have hard grains, alveograph $\mathrm{W}>200$ and $\mathrm{P} / \mathrm{L}$ ratio $<1.1$ ). Type 3 lines are hard grain lines with extensible but weak gluten (alveograph $\mathrm{W}=150-200$ and $\mathrm{P} / \mathrm{L}$ ratio $<1.0$ ) suitable for handmade products including dense and flat breads and some kinds of noodles. Type $4 \mathrm{a}$ lines $(>11.5 \%$ protein, medium strength and extensible) are suitable for steamed bread (southern Chinese style) and white-salted noodles, while Type $4 \mathrm{~b}$ lines are suitable for biscuits and cakes (very extensible and weak gluten), with both Types $4 \mathrm{a}$ and $4 \mathrm{~b}$ lines having soft grains. Finally, Type 5 lines are the breeding lines with weak and/or tenacious gluten, unsuitable for any product, but are sold as utility or feed wheat, and recommend to be culled from the breeding process.

The analyses described above are performed annually for about 1500 breeding lines selected from the first year yield trial $\left(\mathrm{F}_{7}\right)$ and about 500 lines from the elite yield trial $\left(\mathrm{F}_{9}\right)$ (one field rep). This means that each breeding line that is distributed to the international nurseries has been characterized at least twice for grain quality traits. The grain samples analyzed originate from trials conducted under optimum conditions (full irrigation), which ensures high grain yield but results in medium to low protein content in the samples. This is appropriate as it allows highlighting of the effect of protein quality on the traits analyzed, which is the main trait targeted in the genetic improvement process and not protein content (more influenced by the environment). It is important to note that all lines included in the crossing block each year are also analyzed for quality traits, including the identification of the composition of glutenins ( $G l u-1$ and $G l u-3$ genes) by SDS-PAGE. All these quality evaluations are conducted over a period of about 4 months following the May harvest, so breeders can have the data ready before planting for the next yield testing cycle in November. Following this strategy, genetic gains have been achieved in the program over the past 50 years for important quality traits such as gluten strength $\left(2.31 \times 10^{-4} \mathrm{~J}\right.$ per year for alveograph $\left.\mathrm{W}\right)$ and bread loaf volume $(1.32 \mathrm{~mL}$ per year), while grain yield has continued to increase ${ }^{[12]}$.

For durum wheat, the overall strategy has been to develop lines with suitable quality to be accepted by the pasta-making industry worldwide. This means durum wheat lines with large kernel size, high gluten strength and with high pigment content (of the carotenoid pigment lutein). To achieve this, the following traits are analyzed in all the breeding lines tested in yield trails, from preliminary to advanced and elite trials; grain morphology (test weight and thousand-kernel weight), protein content (by NIR), gluten strength (by SDS-sedimentation), and wholemeal flour yellow color (estimated using the yellow index or bvalue colorimeter, Konica Minolta, Tokyo, Japan). The last three tests are performed on wholemeal flour samples obtained with UDY mills (UDY Corp., Fort Collins, CO, USA) with a $0.5 \mathrm{~mm}$ screen. The correlation between values obtained for wholemeal flour and those of semolina are high and well established ${ }^{[13]}$. This allows the bypassing of the time- and labor-consuming process of milling thousands of samples to refined semolina, while ensuring that genetic progress for those traits is made. The SDSsedimentation index value (SDS-sedimentation volume/ protein content) is calculated to focus the selection process on the protein quality rather than protein quantity. Values of this index higher than 0.9 and $b$ yellow color Minolta values higher than 18 indicate a high standard of grain quality (when the tests are performed on wholemeal flour as mentioned above).

Also for durum wheat, grain quality analysis starts in the preliminary yield trials $\left(\mathrm{F}_{6}\right)$ and is repeated for the next three generations (advanced yield trials $\mathrm{A}$ and $\mathrm{B}$ and elite yield trials). Since the information obtained from full irrigation trials (yield of 7-9 $\mathrm{t} \cdot \mathrm{ha}^{-1}$ ) is very similar to that obtained from trials subjected to drought (yield of 1.5$3 \mathrm{t} \cdot \mathrm{ha}^{-1}$ ), it has been decided to focus selection for quality on data from irrigated trials and use two field replicates for a more accurate estimate of each parameter. In total, about 7000 grain samples are analyzed for the durum program from May to September each year. Therefore, by the time breeding lines are distributed to international nurseries, each has been analyzed at least four times for grain quality traits, which allows the selection of materials with wellknown quality attributes. As a consequence of this extensive, low cost and high-throughput, grain quality evaluation, the frequency of lines distributed in international nurseries with medium to large grains has been above $95 \%$. Similarly, the frequency of outgoing lines with medium-strong gluten has been above $98 \%$. Finally, the frequency of lines distributed in international nurseries with acceptable to outstanding yellow color has increased from 52\% in 2005 to around $75 \%$ from 2014 to 2017 (Ammar et al., unpublished data).

\section{Genetic improvement of nutritional quality}

Nutritional quality could be defined as the capacity of a food to provide enough nutrients for a correct mental and physical development and a healthy life of human beings. This has become an important priority for breeding programs of all crops, particularly for the staples (such as wheat, maize, rice and cassava) that represent a large proportion of the food and calories in developing countries. In many of these countries, the diets are low in 
meat, poultry, fish and fruits, and provide insufficient micronutrients. This has resulted in widespread micronutrient deficiency (also known as hidden hunger) and is one of the most important challenges currently facing humanity. The lack of adequate levels of essential vitamins and minerals (particularly $\mathrm{Fe}, \mathrm{Zn}$ and provitamin A carotenoids) affects more than two billion people ${ }^{[14]}$. Food fortification, which involves adding of micronutrients to the food, and supplementation has been an important way to address this kind of malnutrition. However, these efforts are highly dependent on funding and on the presence of a specific infrastructure, and the impact is usually restricted to urban areas. Biofortification, which involves breeding crops that produce edible parts with higher micronutrients concentrations, offers a sustainable solution to increase food and nutritional security for millions of resource-poor consumers where major staples provide most of their dietary energy ${ }^{[15]}$. Through biofortification, the benefits reach the total population in both urban and rural areas, and it will not require continued investment once biofortified cultivars have been developed and deployed.

Wheat is a valuable source of micronutrients and other bioactive components, but the levels of some of these are not high enough to meet the daily requirements of people in countries where wheat represents the main source of calories. CIMMYT is leading the partnership-based global effort within the HarvestPlus project to breed competitive bread wheat cultivars with $40 \%$ higher $\mathrm{Zn}$ concentration (i.e., an increase of $12 \mathrm{mg} \cdot \mathrm{kg}^{-1}$ ) over the current commercial cultivars grown in the target regions of South $\mathrm{Asia}^{[16]}$. This is the primary target nutrient for wheat, as millions of resource-poor wheat consumers in South Asia and Africa are prone to Zn deficiency. This micronutrient has acceptable bioavailability in wheat grain (around 25\% ${ }^{[15]}$. Also, enough genetic variability has been detected for this micronutrient in the wheat genetic resources $^{[17-19]}$, which makes breeding to develop novel wheat cultivars with higher Zn concentration possible. Current breeding efforts at CIMMYT have focused on transferring genes governing increased $\mathrm{Zn}$ and $\mathrm{Fe}$ from Triticum spelta, Triticum dicoccon based synthetics, landraces, and others reported high $\mathrm{Zn}$ and Fe sources to highyielding elite wheat backgrounds. New hexaploid synthetic wheat and other donor parents with significantly higher $\mathrm{Zn}$ and $\mathrm{Fe}$ concentrations were used as donor parents for a limited-backcross breeding approach onto adapted CIMMYT wheat parents ${ }^{[16,20]}$. Plants are then selected for particular agronomic and disease resistance traits all through the breeding process. Selection for high $\mathrm{Zn}$ starts in the $\mathrm{F}_{5}$ generation onwards. For $\mathrm{Zn}$ whole grain concentration measurement, energy-dispersive X-ray fluorescence spectrometry is used, which offers a fast and economical method for the assessment of $\mathrm{Zn}$ and other micronutrients ( $\mathrm{Fe}$ and $\mathrm{Se}$ ) in biofortification programs ${ }^{[21]}$. Processing and end-use quality are also included in this breeding program as described for the bread wheat program. Following this process, five biofortified wheat cultivars have been released, cv. Bari Gom 33 in Bangladesh, cvs Zinc Shakti (Chitra), WB02 and HPBW-01 in India, and cv. Zincol 2016 in Pakistan (Table 2). All these cultivars have high grain yield (at least as high as other cultivars released in the same regions) and on average $10 \mathrm{ppm}(29 \%)$ more $\mathrm{Zn}$ in the grain ${ }^{[22]}$. These cultivars are already being grown by farmers and nutrition trials with biofortified wheat have shown a reduction in child morbidity ${ }^{[23]}$. Therefore, this project has demonstrated the feasibility of breeding for nutritional quality in wheat. These breeding activities could be expanded in the future to the whole breeding program and to other grain components (e.g., fiber and vitamins) to enhance the nutritious and healthy properties of the wheat grain.

\section{Wheat grain quality research activities}

In addition to the activities of the Wheat Chemistry and Quality Laboratory conducted as support to the breeding programs, significant time and resources are allocated to diverse research projects that aim to extend our knowledge of wheat grain quality. The main topics addressed in these research activities are (1) methodologies to analyze grain quality traits, (2) genetic control and environmental effects on quality traits, (3) characterization of genetic resources for quality improvement, and (4) diversifying grain properties for novel uses.

The use of accurate, fast and low-cost methods is important for a wheat quality laboratory (such as that of CIMMYT) to enable rapid analysis of the large number of

Table 2 Wheat biofortified cultivars released

\begin{tabular}{lccc}
\hline Cultivar & Country & Year & Pedigree \\
\hline Zinc Shakti (Chitra) & India & 2012 & CROC1/AE.SQUARROSA (210)//INQALAB91*2/KUKUNA/3/ \\
Pincol 2016 & Pakistan & 2016 & OASIS/SKAUZ//4*BCN/3/2*PASTOR/4/T.SPELTAPI348449/5/BACEU\#1/6/ \\
& WBLL1*2/CHAPIO \\
WB02 & India & 2017 & T. DICOCCON, CI9309/AE.SQUARROSA (409)//MUTUS/3/2*MUTUS \\
HPBW-01 & India & 2017 & T. DICOCCON, CI9309/AE.SQUARROSA (409)//MUTUS/3/2*MUTUS \\
Bari Gom 33 & Bangladesh & 2017 & KACHU/SOLALA \\
\hline
\end{tabular}


samples generated by breeding programs. Significant time is invested in developing and adapting methods to more efficiently analyze grain quality traits that are currently used in selection by the breeders, and to provide new ones to be incorporated into breeding pipelines. Several methods have been scaled down in the last years, including solvent retention capacity (from 5 to $0.3 \mathrm{~g})^{[24]}$ and phytic acid determination ${ }^{[25]}$, with the objective of reducing the amount of flour and reagents required to run the tests and increase the throughput. Some modifications have been applied to other official methods (most of them from AACC) to improve the correlation of the data generated by different laboratory tests. This is the case for the water absorption used for the mixograph, alveograph and breadmaking analysis, which is based on different criteria from the official methods, and modified to make it dependent on the solvent retention capacity profile for the three tests ${ }^{[11]}$. CIMMYT has also collaborated with suppliers of laboratory equipment to improve their products, as in the case of the SeedCount (Next Instruments, Condell Park, NSW, Australia) for which a calibration to evaluate the number of grains affected with yellow berry was optimized.

Genetic control of quality traits is also one of the important topics for research at CIMMYT. Increasing the knowledge in this area will make breeding for grain quality more efficient in the future. Currently, most of the important quality traits are associated with well-known genes. For most of these genes, several alleles have been described, and in some cases the alleles have been associated with differences in the expression of different quality traits ${ }^{[26-29]}$. But in many other cases, there is a gap in knowledge to explain how specific alleles affects quality and more research is still necessary to understand how different genes (and their alleles) interact to generate a particular phenotype. At CIMMYT's Wheat Chemistry and Quality Laboratory, several studies have been conducted of the effect of allelic composition at the Glu-1 and Glu-3 loci, known to strongly influence gluten properties and end-use quality ${ }^{[30-35]}$. This represents a substantial effort for the coming years due to the great diversity of available gluten alleles in the wheat pool and the complexity of this protein network. The effects of other genes (i.e., other than the glutenins) on grain texture, flour color and bread-making quality are also being evaluated. The effects of the genes are also evaluated for their interactions with the environment and how these interactions affect the expression of quality traits. Due to the global focus of the CIMMYT breeding programs, it is important to know how different environmental conditions will affect the expression of the grain quality in the germplasm developed. Several studies with wheat genotypes grown under drought and heat stress have been conducted $^{[13,31,33,36,37]}$. General responses to these stresses have been identified as well as the magnitude of the $\mathrm{G} \times \mathrm{E}$ interactions, which is important for the design of breeding strategies involving quality improvement (single- vs. multi-environment testing).

Finally, the investigation of wheat genetic resources to discover sources of new genes and alleles, and quality traits that are not common in the modern wheat pool is another important component of CIMMYT's research portfolio. Collections of bread and durum wheat landraces, wheat ancestors (including einkorn, emmer and spelt), and wild relatives (mainly Aegilops species) have been evaluated for traits related to wheat quality ${ }^{[38-46]}$. In these collections, novel genetic variability and promising genotypes with atypical phenotypic characteristics have been identified and can be considered as valuable parent materials to be exploited in breeding programs targeting improvement of quality traits and widening the range of the end-uses for wheat grain. Consequently, several projects are currently focusing on expanding the uses for durum wheat, including the development of durum genotypes with soft grain texture ${ }^{[47]}$ and with enhanced gluten properties through the introgression of bread wheat glutenins genes such as $G l u-D 1$.

\section{Conclusions}

At CIMMYT, wheat quality improvement is a central component of all its breeding efforts, so the Wheat Chemistry and Quality Laboratory represents an integral part of these breeding programs. Wheat progenitors and advanced lines developed by breeders are assessed for diverse quality attributes to identifying those that fulfill the requirements for milling, processing, end-use and nutritional quality in different target regions. Also, considerable research is being conducted to improve the efficiency of the integration of wheat quality traits into the breeding programs.

Acknowledgements Funding for wheat quality improvement at CIMMYT is provided by CGIAR CRP WHEAT, HarvestPlus Challenge Program, Durable Genetic Gains in Wheat Project (Bill and Melinda Gates Foundation and DFID through a Grant to Cornell University), and MasAgro Trigo (Sagarpa, Mexico)

Compliance with ethics guidelines Carlos Guzmán, Karim Ammar, Velu Govindan, and Ravi Singh declare that they have no conflicts of interest or financial conflicts to disclose.

This article is a review and does not contain any studies with human or animal subjects performed by any of the authors.

\section{References}

1. Feldman M. Wheats. In: Smartt J, Simmonds N W, eds. Evolution of Crop Plants. Harlow, UK: Longman Scientific and Technical, 1995, 185-192

2. FAOSTAT. Food and agriculture data, 2017. Available at FAO 
website on March 25, 2019

3. Shewry P R. Wheat. Journal of Experimental Botany, 2009, 60(6): $1537-1553$

4. Peña-Bautista R J, Hernandez-Espinosa N, Jones J M, Guzmán C, Braun H J. CIMMYT series on carbohydrates, wheat, grains, and health: wheat-based foods: their global and regional importance in the food supply, nutrition, and health. Cereal Foods World, 2017, 62 (5): 231-249

5. Fan M S, Zhao F J, Fairweather-Tait S J, Poulton P R, Dunham S J, McGrath S P. Evidence of decreasing mineral density in wheat grain over the last 160 years. Journal of Trace Elements in Medicine and Biology, 2008, 22(4): 315-324

6. Lantican M A, Braun H J, Payne T S, Singh R P, Sonder K, Baum M, van Ginkel M, Erenstein O. Impacts of International Wheat Improvement Research, 1994-2014. Veracruz: CIMMYT, 2016

7. Edwards M A, Osborne B G, Henry R J. Puroindoline genotype, starch granule size distribution and milling quality of wheat. Journal of Cereal Science, 2010, 52(2): 314-320

8. Matsuo R, Dexter J. Relationship between some durum wheat physical characteristics and semolina milling properties. Canadian Journal of Plant Science, 1980, 60(1): 49-53

9. Morris C F. Puroindolines: the molecular genetic basis of wheat grain hardness. Plant Molecular Biology, 2002, 48(5-6): 633-647

10. Wrigley C W, Batey I L, Skylas D J, Sharp P J. The Unique Balance of Wheat Quality. St. Paul: AACCI Press, 2006

11. Guzmán C, Posadas-Romano G, Hernández-Espinosa N, MoralesDorantes A, Peña R J. A new standard water absorption criteria based on solvent retention capacity (SRC) to determine dough mixing properties, viscoelasticity, and bread-making quality. Journal of Cereal Science, 2015, 66: 59-65

12. Guzmán C, Autrique E, Mondal S, Huerta-Espino J, Singh R P, Vargas M, Crossa J, Amaya A, Peña R J. Genetic improvement of grain quality traits for CIMMYT semi-dwarf spring bread wheat varieties developed during 1965-2015: 50 years of breeding. Field Crops Research, 2017, 210: 192-196

13. Guzmán C, Autrique J E, Mondal S, Singh R P, Govindan V, Morales-Dorantes A, Posadas-Romano G, Crossa J, Ammar K, Peña R J. Response to drought and heat stress on wheat quality, with special emphasis on bread-making quality in durum wheat. Field Crops Research, 2016, 186: 157-165

14. WHO. The World Health Report. Geneva: World Health Organization, 2017

15. Bouis H E, Hotz C, McClafferty B, Meenakshi J V, Pfeiffer W H. Biofortification: a new tool to reduce micronutrient malnutrition. Food and Nutrition Bulletin, 2011, 32(1_Suppl1): S31-S40

16. Velu G, Singh R, Huerta-Espino J, Peña J, Ortiz-Monasterio I. Breeding for enhanced zinc and iron concentration in CIMMYT spring wheat germplasm. Czech Journal of Genetics and Plant Breeding, 2011, 47: S174-S177

17. Cakmak I, Ozkan H, Braun H, Welch R, Romheld V. Zinc and iron concentrations in seeds of wild, primitive, and modern wheats. Food and Nutrition Bulletin, 2000, 21(4): 401-403

18. Gomez-Becerra H F, Yazici A, Ozturk L, Budak H, Peleg Z, Morgounov A, Fahima T, Saranga Y, Cakmak I. Genetic variation and environmental stability of grain mineral nutrient concentrations in Triticum dicoccoides under five environments. Euphytica, 2010,
171(1): 39-52

19. Monasterio I, Graham R. Breeding for trace minerals in wheat. Food and Nutrition Bulletin, 2000, 21(4): 392-396

20. Guzmán C, Medina-Larqué A S, Velu G, González-Santoyo H, Singh R P, Huerta-Espino J, Ortiz-Monasterio I, Peña R J. Use of wheat genetic resources to develop biofortified wheat with enhanced grain zinc and iron concentrations and desirable processing quality. Journal of Cereal Science, 2014, 60(3): 617-622

21. Paltridge N G, Milham P J, Ortiz-Monasterio J I, Velu G, Yasmin Z, Palmer L J, Guild G E, Stangoulis J C R. Energy-dispersive X-ray fluorescence spectrometry as a tool for zinc, iron and selenium analysis in whole grain wheat. Plant and Soil, 2012, 361(1-2): 261269

22. Singh R P, Velu G. Zinc-biofortified wheat: harnessing genetic diversity for improved nutritional quality. Science Brief: Biofortification, 2017, (1): 1-4

23. Sazawal S, Dhingra U, Dhingra P, Dutta A, Deb S, Kumar J, Devi P, Prakash A. Efficacy of high zinc biofortified wheat in improvement of micronutrient status, and prevention of morbidity among preschool children and women - a double masked, randomized, controlled trial. Nutrition Journal, 2018, 17(1): 86

24. Guzmán C, Mondal S, Govindan V, Autrique J E, Posadas-Romano G, Cervantes F, Crossa J, Vargas M, Singh R P, Peña R J. Use of rapid tests to predict quality traits of CIMMYT bread wheat genotypes grown under different environments. LWT-Food Science and Technology, 2016, 69: 327-333

25. Magallanes-López A M, Hernandez-Espinosa N, Velu G, PosadasRomano G, Ordoñez-Villegas V M G, Crossa J, Ammar K, Guzmán C. Variability in iron, zinc and phytic acid content in a worldwide collection of commercial durum wheat cultivars and the effect of reduced irrigation on these traits. Food Chemistry, 2017, 237: 499505

26. Chen F, Li H, Li X, Dong Z, Zuo A, Shang X, Cui D. Alveograph and Mixolab parameters associated with Puroindoline-D1 genes in Chinese winter wheats. Journal of the Science of Food and Agriculture, 2013, 93(10): 2541-2548

27. Cornish G B, Békés F, Eagles H A, Payne P I. Prediction of dough properties for bread wheats. In: Wrigley C W, Batey I L, Skylas D J, Sharp P J, eds. The Unique Balance of Wheat Quality. St. Paul: AACCI Press, 2006

28. Guzmán C, Alvarez J B. Wheat waxy proteins: polymorphism, molecular characterization and effects on starch properties. Theoretical and Applied Genetics, 2016, 129(1): 1-16

29. Morris C F, Bhave M. Reconciliation of D-genome puroindoline allele designations with current DNA sequence data. Journal of Cereal Science, 2008, 48(2): 277-287

30. Cruz E M, Rangel E E, Mir H E V, Bautista R J P. Contribution of Glu-B1, Glu-D1 and Glu-B3 loci to dough quality of bread wheat. Revista Fitotecnia Mexicana, 2012, 35(2): 135-142 (in Spanish)

31. Hernández N, Posadas G, Cervantes F, González H I, Santacruz A, Benítez I, Peña R J. Contribution of combinations of glutenins to the gluten characteristics of wheat recombinant populations. Revista Fitotecnia Mexicana, 2013, 36(1): 45-51 (in Spanish)

32. Guzmán C, Xiao Y, Crossa J, González-Santoyo H, Huerta J, Singh $\mathrm{R}$, Dreisigacker S. Sources of the highly expressed wheat bread making $(w b m)$ gene in CIMMYT spring wheat germplasm and its 
effect on processing and bread-making quality. Euphytica, 2016, 209(3): 689-692

33. Magallanes-López A M, Ammar K, Morales-Dorantes A, GonzálezSantoyo H, Crossa J, Guzmán C. Grain quality traits of commercial durum wheat varieties and their relationships with drought stress and glutenins composition. Journal of Cereal Science, 2017, 75: 1-9

34. Martínez-Cruz E, Espitia-Rangel E, Villaseñor-Mir H, MolinaGalán J, Benítez-Riquelme I, Santacruz-Varela A, Peña-Bautista R. Dough rheology of wheat recombinant lines in relation to allelic variants of Glu-1 and Glu-3 loci. Cereal Research Communications, 2011, 39(3): 386-393

35. Velu G, Singh R P, Cardenas M E, Wu B, Guzmán C, OrtizMonasterio I. Characterization of grain protein content gene ( $G P C$ $B 1$ ) introgression lines and its potential use in breeding for enhanced grain zinc and iron concentration in spring wheat. Acta Physiologiae Plantarum, 2017, 39(9): 212

36. Hernández-Espinosa N, Mondal S, Autrique E, Gonzalez-Santoyo H, Crossa J, Huerta-Espino J, Singh R P, Guzmán C. Milling, processing and end-use quality traits of CIMMYT spring bread wheat germplasm under drought and heat stress. Field Crops Research, 2018, 215: 104-112

37. Velu G, Guzmán C, Mondal S, Autrique J E, Huerta J, Singh R P. Effect of drought and elevated temperature on grain zinc and iron concentrations in CIMMYT spring wheat. Journal of Cereal Science, 2016, 69: 182-186

38. Ayala M, Guzmán C, Alvarez J B, Peña R J. Characterization of genetic diversity of puroindoline genes in Mexican wheat landraces. Euphytica, 2013, 190(1): 53-63

39. Ayala M, Alvarez J B, Yamamori M, Guzmán C. Molecular characterization of waxy alleles in three subspecies of hexaploid wheat and identification of two novel Wx-B1 alleles. Theoretical and Applied Genetics, 2015, 128(12): 2427-2435

40. Ayala M, Guzmán C, Peña R J, Alvarez J B. Genetic diversity and molecular characterization of puroindoline genes (Pina-D1 and Pinb-D1) in bread wheat landraces from Andalusia (Southern Spain). Journal of Cereal Science, 2016, 71: 61-65

41. Ayala M, Guzmán C, Peña R J, Alvarez J B. Diversity of phenotypic (plant and grain morphological) and genotypic (glutenin alleles in Glu-1 and Glu-3 loci) traits of wheat landraces (Triticum aestivum) from Andalusia (Southern Spain). Genetic Resources and Crop Evolution, 2016, 63(3): 465-475

42. Cuesta S, Guzmán C, Alvarez J B. Molecular characterization of novel LMW-i glutenin subunit genes from Triticum urartu Thum. ex Gandil. Theoretical and Applied Genetics, 2015, 128(11): 21552165

43. Cuesta S, Guzmán C, Alvarez J B. Molecular characterisation of novel LMW-m and LMW-s genes from four Aegilops species (Sitopsis section) and comparison with those from the Glu-B3 locus of common wheat. Crop \& Pasture Science, 2016, 67(9): 938-947

44. Cuesta S, Alvarez J B, Guzmán C. Identification and molecular characterization of novel LMW-m and-s glutenin genes, and a chimeric-m/-i glutenin gene in 1A chromosome of three diploid Triticum species. Journal of Cereal Science, 2017, 74: 46-55

45. Guzmán C, Ortega R, Yamamori M, Peña R J, Alvarez J B. Molecular characterization of two novel null waxy alleles in Mexican bread wheat landraces. Journal of Cereal Science, 2015, 62: $8-14$

46. Vikram P, Franco J, Burgueño-Ferreira J, Li H, Sehgal D, Saint Pierre C, Ortiz C, Sneller C, Tattaris M, Guzmán C, Sansaloni C P, Ellis M, Fuentes-Davila G, Reynolds M, Sonders K, Singh P, Payne T, Wenzl P, Sharma A, Bains N S, Singh G P, Crossa J, Singh S. Unlocking the genetic diversity of Creole wheats. Scientific Reports, 2016, 6(1): 23092

47. Morris C F, Casper J, Kiszonas A M, Fuerst E P, Murray J, Simeone M C, Lafiandra D. Soft kernel durum wheat - a new bakery ingredient? Cereal Foods World, 2015, 60(2): 76-83 